\title{
Editorial
}

\section{Pandemia (Covid-19) e cenário político sombrio: efeitos colaterais na educação brasileira}

Leonice Matilde Richter ${ }^{1}$ Universidade Federal de Uberlândia

Vilma Aparecida de Souza ${ }^{2}$ Universidade Federal de Uberlândia

Maria Vieira Silva ${ }^{3}$ Universidade Federal de Uberlândia

Raquel Aparecida Souza ${ }^{4}$ Universidade Federal de Uberlândia

A avaliação do cenário atual evidencia um momento sombrio da nossa história, seja pela pandemia que assola o mundo com o coronavírus (COVID-19), uma doença infecciosa causada pelo vírus SARS-CoV-2, que já provocou mais de 4,5 milhões de mortes no mundo e, no Brasil, mais de 594 mil, mas também pelo momento político que tem sido caracterizado por fundamentos extremamente conservadores, associados à ampliação dos interesses do mercado. De tal modo, a realidade trágica, que marca a nossa história diante das famílias enlutadas ou que sofrem os efeitos deletérios de um contexto pandêmico de tamanha proporção, associa-se, dentre outros, a efeitos econômicos e socioculturais das políticas antidemocráticas e

\footnotetext{
${ }^{1}$ Editora adjunta da Comissão Editorial da Revista Educação e Políticas em Debate. Doutora em Educação. Professora associada da Faculdade de Educação (Faced/UFU) com atuação no Curso de Pedagogia e nos cursos de Mestrado e Doutorado do Programa de Pós-Graduação em Educação desta mesma instituição. E-mail: leonice@ufu.br. Lattes: http://lattes.cnpq.br/9049041703208746. ORCID: https://orcid.org/0000-0001-7109-3257.

${ }^{2}$ Editora adjunta da Comissão Editorial da Revista Educação e Políticas em Debate. Doutora em Educação. Professora adjunta da Faculdade de Educação (Faced/UFU) com atuação no Curso de Pedagogia e nos cursos de Mestrado e Doutorado do Programa de Pós-Graduação em Educação desta mesma instituição. E-mail: vilmasouza@ufu.br. Lattes. http://lattes.cnpq.br/1776641740982053. ORCID: https://orcid.org/0000-0001-9420-0908.

${ }^{3}$ Presidente da Comissão Editorial da Revista Educação e Políticas em Debate. Doutora em Educação pela Universidade Estadual de Campinas (UNICAMP), com estágio de pós-doutorado, realizado no Centre de Recherches Sociologiques e Politiques de Paris-Université Paris VIII. Professora Titular de Políticas e Gestão da Faculdade de Educação da Educação da Universidade Federal de Uberlândia. Bolsista de Produtividade em Pesquisa do Conselho Nacional de Desenvolvimento Científico e Tecnológico (CNPq). Coordenadora do Grupo de Pesquisa Polis, Políticas, Educação e Cidadania da UFU. Diretora de Formação e Desenvolvimento da Associação Nacional de Política e Administração da Educação (ANPAE). Membro do Grupo de Trabalho Estado e Políticas Educacionais da Associação Nacional de Pós-graduação e Pesquisa em Educação (ANPEd) e membro do Centro de Estudos Educação e Sociedade (CEDES). E-mail: mvieiraufu@ufu.br. Lattes: http://lattes.cnpq.br/0726794592785841. ORCID: https://orcid.org/o000-0002-4510-0844.

${ }^{4}$ Editora adjunta da Comissão Editorial da Revista Educação e Políticas em Debate. Doutora em Educação pela Universidade de Brasília. Docente da Universidade Federal de Uberlândia, campus Pontal, no curso de Pedagogia. E-mail: raquelas@ufu.br. Lattes: http://lattes.cnpq.br/9208469507359517. Orcid: https://orcid.org/0000-0001-5906-0671.
} 
neoliberais, que colocam muitos em situação de abandono por parte do Estado, ampliando as consequências lancinantes da pandemia.

Compreende-se, assim, que as sequelas da pandemia são expressivamente distintas, especialmente para aqueles que sofrem os efeitos desse duplo processo de "morte" - ameaça do vírus SARS-CoV-2 e restrição de direitos, o que amplia a situação de vulnerabilidade e de pobreza dos(as) trabalhadores(as). De tal modo, o contexto pandêmico é agravado pela nossa atual conjuntura política.

O discurso e as manifestações da extrema direita ampliaram-se progressivamente nos últimos anos e, em sintonia, partidos políticos promulgam tais ideais e ocupam cada vez mais espaço no cenário político em diferentes países, como analisa Wendy Bron (2020), ao destacar os neonazistas no parlamento alemão, neofascismo na Itália, neonacionalismo branco na Escandinávia, o recente regime autoritário de Donald Trump e, nessa lista, acrescente-se a atual gestão, no Brasil, de Jair Messias Bolsonaro do Partido Social Liberal (PSL, 2019) e sem partido atualmente. Para a autora, cresce, nas redes sociais, manifestações racistas e de ódio que estavam à sombra e que agora encontram espaço para publicização. Há, nesse movimento, ampliação de um processo extremamente nocivo à humanidade, uma vez que associa "libertarianismo, moralismo, autoritarismo, nacionalismo, ódio ao Estado, conservadorismo cristão e racismo" (BRON, 2020, p.10) a preceitos econômicos neoliberais.

No Brasil, a ascensão dos discursos, das manifestações e das práticas antidemocráticas avolumou-se, especialmente, após o golpe jurídico, midiático e parlamentar (SAVIANI, 2018) que levou Dilma Rousseff (Partido dos Trabalhadores - PT), a única mulher democraticamente eleita à presidência no país, a ser destituída, depois de ter recebido o voto de $51,64 \%$ da população brasileira. Como avalia Freitas (2018, p.10), 2016 representa a saída de cena do desenvolvimentismo que tinha, de certo modo, freado o neoliberalismo insuflado pela coalização centro-direita. Segundo análise do autor, essa é uma matéria ainda em aberto, mas fazendo justiça, "a nova coalisão petista não foi uma linha nem reta nem célere em direção à reforma empresarial como teria sido se a coalização PSDB/PFL tivesse permanecido no poder”. Contudo, o golpe, que levou Michel Temer (Movimento Democrático Brasileiro MDB) à presidência, acarretou a destituição do capitalismo desenvolvimentista e a (re)centralização absoluta do liberalismo econômico (neoliberalismo).

Desde então, inúmeras foram as perdas de direitos da classe trabalhadora e, dentre elas, destaca-se a Lei ${ }^{\circ} 13.467$, de 13 de julho de 2017, com a Reforma Trabalhista; a Emenda Constitucional $\mathrm{n}^{\circ}$ 103, de 12 de novembro de 2019, com a Reforma da Previdência; a atual proposta em curso de Emenda à Constituição no 32/2020 do Poder Executivo, que altera dispositivos sobre servidores e empregados públicos e modifica a 
organização da administração pública direta e indireta de qualquer dos Poderes da União, dos estados, do Distrito Federal e dos municípios, ações em grande medida justificadas pela Emenda Constitucional n ${ }^{\circ}$ 95/2016, que instituiu o Novo Regime Fiscal por meio do qual se estabeleceram limites individualizados para as despesas primárias, congelando tais gastos por vinte exercícios financeiros. Esses e outros dispositivos legais têm precarizado as condições de vida da população brasileira, alargando os índices de pobreza e de extrema pobreza no país. Tais contrarreformas estão em consonância com a defesa da economia de livre mercado, com os interesses de grupos econômicos amplamente influentes, que têm afetado diretamente os direitos sociais.

De tal modo, evidencia-se que a pandemia assolou o mundo e, sobremaneira, o Brasil em um momento crítico. E o agravamento da situação ocorreu, ainda, diante do negacionismo da pandemia por parte do próprio Presidente Jair Bolsonaro. Inúmeras foram as manifestações públicas, minimizando a gravidade da Covid-19 e desestimulando o uso de medidas de proteção, associadas ao estímulo a tratamentos sem comprovação científica. Como aponta Morel (2021),

Notícias falsas afirmam que o colapso funerário de Manaus (AM) não ocorreu. Cientistas que pesquisam os efeitos da cloroquina sofrem ataques. Declarações do presidente da República minimizam a gravidade da Covid-19. Essas são algumas das recorrentes expressões do negacionismo da pandemia no Brasil hoje que se articulam com outros movimentos negacionistas que vêm ganhando força nos últimos anos. Há o negacionismo científico, que tem como principais expoentes atualmente o movimento antivacina e o terraplanismo. Há o negacionismo climático, ancorado na negação do colapso ecológico em curso. Observamos também um crescente negacionismo histórico, baseado na negação de acontecimentos históricos amplamente conhecidos, como a ditadura militar no Brasil e o holocausto. Poderíamos acrescentar ainda outro negacionismo bastante presente na realidade brasileira, até mesmo constituinte do projeto de Estado-Nação no Brasil: o negacionismo do racismo, ancorado no mito da democracia racial. (MOREL, 2021, p. 02 )

Em meio a esse caótico e intencional processo negacionista, diferentes áreas, como a educação, vivem o recrudescimento dos investimentos associado à ausência de políticas sistemáticas e orgânicas para enfrentar os efeitos colaterais da pandemia. Assim, enquanto mantinham a agenda e a reforma empresarial da educação no país, seja no revigoramento da accountability, na centralização curricular, nas políticas de formação docente neotecnicista, no enfraquecimento da gestão democrática e no fortalecimento de preceitos da gestão privada, dentre outros interesses, no campo de enfrentamento da pandemia, pouco investimento e ações no sentido de estruturar e de garantir as condições materiais para a realização das atividades 
educacionais durante a suspensão das aulas presenciais, indicadas em decorrência do decreto Legislativo n. $^{\circ} 6$, de 20 de março de 2020 , em que se reconhecia o estado de calamidade pública.

De acordo com os dados do Instituto Nacional de Estudos e Pesquisas Educacionais Anísio Teixeira (Inep), 99,3\% das escolas brasileiras suspenderam as atividades presenciais, sendo que $90,1 \%$ não retornaram às atividades presenciais no ano letivo de $2020-98,4 \%$ da rede federal, $97,5 \%$ das escolas municipais, $85,9 \%$ das estaduais e $70,9 \%$ das privadas. Tais dados compõem o relatório "Resposta educacional à pandemia de COVID-19 no Brasil" (2021), fruto de um questionário suplementar aplicado entre fevereiro e maio de 2021 como parte da segunda etapa do Censo Escolar 2020. No total, 168.739 escolas responderam ao questionário, percentual que corresponde a 97,2\% (134.606) e 83,2\% (34.133) das redes pública e privada, respectivamente. Segundo o Inep, o objetivo era identificar as ações adotadas pelas escolas brasileiras diante da necessidade de medidas de enfrentamento à disseminação do novo coronavírus.

Os dados do relatório indicam, ainda, que $98 \%$ das escolas do país adotaram estratégias não presenciais de ensino, viabilizadas pela Portaria nº 343, de 17 de março de 2020, que dispunha sobre a substituição das aulas presenciais por aulas em meios digitais enquanto durasse a situação de pandemia do Novo Coronavírus, e pela Medida Provisória n. $^{\circ} 934$, de $1^{\circ}$ de abril de 2020, que estabelecia normas excepcionais sobre o ano letivo da educação básica e do ensino superior, decorrentes das medidas para enfrentamento da situação de emergência de saúde pública, e dispensava-se, no ensino de educação básica, em caráter excepcional, a obrigatoriedade da observância do mínimo de dias de efetivo trabalho escolar, assim como no Art. $2^{\circ}$ em que se definia que as instituições de educação superior estavam dispensadas, em caráter excepcional, da obrigatoriedade de observância ao mínimo de dias de efetivo trabalho acadêmico.

Ainda, segundo os dados do Inep, no Brasil, quanto às Estratégias de Retorno às Atividades Presenciais (Ano Letivo de 2020), apenas 56,8\% tiveram adequação/ampliação da infraestrutura física das escolas (instalação de pias para a lavagem das mãos, construção de salas para reduzir o número de alunos por turma, aumento da ventilação natural), e segundo o relatório, $85 \%$ das escolas/redes propiciaram a capacitação dos(as) profissionais para o cumprimento das medidas sanitárias para a identificação dos sintomas da Covid-19 e para o monitoramento dos motivos de ausência dos(as) estudantes. Quanto ao contexto de retorno às atividades presenciais, os dados indicam que $50 \%$ dos profissionais e/ou estudantes foram afastados por Covid-19 depois do retorno presencial.

A pandemia da Covid 19 afetou todos os níveis e todas as modalidades da educação, com especificidades que carecem de pesquisas e de estudos no sentido de compreender os efeitos 
das políticas empreendidas. A proteção à vida, como princípio fundamental, orienta para o necessário distanciamento social no contexto de pandemia. Para tanto, há de se garantir medidas para enfrentar essa crise sanitária e condições para evitar a intensificação da desigualdade e novos processos de exclusão no âmbito educacional. Contudo, a falta de uma política coordenada, com ações sistêmicas entre união e entes federados, com a efetivação de investimento para prover as condições necessárias, seja para alternativas durante o distanciamento social, tanto aos(às) estudantes quanto aos(às) profissionais da educação, seja para o processo de retorno às atividades presenciais, provoca a intensificação das injustiças de um sistema já marcado pelas desigualdades.

Por isso, o início das atividades remotas e os movimentos de retorno das atividades presenciais sem as devidas condições agravam a realidade e afetam a educação pública, gratuita e de qualidade.

Cabe ressaltar, ainda, os interesses privatistas dos reformadores da educação (FREITAS, 2018, p. 31), que no atual contexto seguem defendendo "a educação a partir de sua concepção de sociedade baseada em um livre mercado cuja própria lógica produz o avanço social com qualidade, depurando a ineficiência através da concorrência” e que a" eficiência do sistema educacional seria atingida quando a atividade educacional estivesse sob controle empresarial”. Assim, há de se destacar os riscos de as atividades remotas, empreendidas no contexto de pandemia, serem utilizadas como forma de defesa e de venda de produtos e de plataformas educacionais, estimulando as parcerias públicoprivada, ampliando a precarização do ensino e do trabalho docente, o que requer pesquisas e estudos sistemáticos das políticas públicas em curso.

Diante de um cenário de tantos retrocessos políticos e de pandemia, a Revista Educação e Políticas em Debate pretende colaborar com as reflexões concernentes, especialmente, às políticas emanadas pelo governo no atual contexto, assim como as formas de resistências engendradas por professores(as), pesquisadores(as) e associações voltadas à defesa de uma educação crítica e justa. Nessa direção, a presente edição apresenta o dossiê "Direito à educação básica e superior em tempos de pandemia - políticas de permanência e qualidade”, composto por treze artigos e uma entrevista, organizado pelas professoras Klivia de Cássia Silva Nunes (ICHPO-UFU) e Valéria Moreira Rezende (ICHPO-UFU), a quem externalizamos os nossos agradecimentos ao trabalho e à dedicação empreendida.

Além do dossiê, o presente número conta com 6 artigos na seção "Demanda Contínua”, que abordam problemáticas da área de políticas educacionais a partir das contribuições de pesquisadores de diferentes regiões do país. O primeiro artigo de autoria de Menissa Bessa, da Universidade Federal do Tocantins, apresenta considerações sobre 
o desenvolvimento de pesquisa no campo das políticas educacionais e a abordagem do ciclo de políticas. A exposição, ao longo do manuscrito, deu-se em uma perspectiva descritiva/analítica, com base em um levantamento bibliográfico.

O artigo intitulado "Fundamentos ideológicos e normativos do 'Programa Escola sem Partido’ e seus desdobramentos na educação brasileira” é de autoria de Fernanda Motta de Paula Resende, de Julio Cesar Torres, de Maria Denise Guedes, docentes da Universidade Estadual Paulista “Júlio de Mesquita Filho, e de Glariston Resende, do Tribunal de Justiça do Estado de São Paulo. Os(as) autores(as) apresentam os resultados da pesquisa sobre os fundamentos ideológicos e normativos do "Programa Escola sem Partido" - Projeto de Lei (PL) n $n^{\circ}$ 867/2015, com base em uma análise documental e bibliográfica. Evidenciam-se, no manuscrito, as fragilidades dos fundamentos ideológicos do PL, suas inconsistências lógicoteóricas e como retomam valores seculares de nossa sociedade.

O texto "Presença da Nova Gestão Pública na educação básica do Distrito Federal - 2007-2020", de Maria Abádia da Silva e de Ricardo Gonçalves Pacheco, ambos da Universidade de Brasília, analisa circunstâncias históricas que gestaram a Nova Gestão Pública (NGP), seus fundamentos, finalidades e caraterísticas na esteira da expansão das políticas neoliberais, conduzidas por grupos econômicos, por empresários e por governos neoconservadores ávidos por crescimento econômico. O manuscrito analisa as produções científicas de portais eletrônicos e das legislações federal e distrital e considera que as instituições sociais estão sendo reestruturadas sob a lógica da racionalidade, da flexibilidade, da competitividade e da privatização dos serviços públicos. Aponta, ainda, que, no Distrito Federal, governo e entusiastas dos princípios empresariais na Educação Básica adotaram mecanismos jurídicos, políticas de regulação e parcerias públicoprivadas que coexistem com os valores e com os princípios democráticos.

As autoras Rozemeiry dos Santos Marques Moreira e Waléria Andrade Martins, da Universidade Federal de Mato Grosso do Sul, no texto "Política De Avaliação Externa: o discurso da qualidade ou a qualidade do discurso?" abordam o discurso da qualidade da política de avaliação externa e a qualidade do discurso da escola com base no que se entende por qualidade da educação na Constituição Federal de 1988, na Lei de Diretrizes e Bases da Educação Nacional de 1996 e no tex to da política de avaliação externa. Segundo as autoras, as peculiaridades de cada escola tendem a dificultar a interpretação do texto da política, sobretudo em relação à qualidade, por ser um conceito relacional, de modo que traduzir políticas em práticas implica sua recriação em face de contextos distintos e por diferentes sujeitos.

Circe Mara Marques e Gabriela Senger, da Universidade Comunitária da Região de Chapecó, no manuscrito intitulado "Um olhar sobre os conflitos e sua resolução em uma escola 
pública de ensino fundamental de Chapecó-SC", mapeiam os conflitos que ocorrem entre as crianças do primeiro ao quinto ano e os modos como esses conflitos são mediados por gestores e por professores(as) de uma escola pública da região de Chapecó, com dados produzidos a partir de observações e de entrevistas com duas gestoras escolares e com nove professoras.

As autoras Caroline Leal (Prefeitura Municipal de Porto Alegre) e Carla Garcia Bottega (Universidade Estadual do Rio Grande do Sul) analisam o absenteísmo-doença entre professores(as) da Rede Municipal de Ensino de Porto Alegre (RME/POA) na série temporal de 2014-2019. Por meio da Estatística Descritiva, analisaram quantitativamente os indicadores a respeito das Licenças Tratamento de Saúde (LTS), constatando-se um significativo aumento no número delas e de docentes em LTS, bem como a redução do número de dias por licença e de dias de licença por servidor(a).

Por fim, agradecemos as contribuições $\operatorname{dos}($ as) autores(as), dos(as) pareceristas, $\operatorname{dos}($ as $)$ revisores(as) das línguas Portuguesa, Inglesa e Francesa, da secretaria de periódicos da Faculdade de Educação (Faced) da UFU e dos membros do Conselho Editorial.

Desejamos a todos e a todas uma boa leitura!

\section{Referências}

BRASIL. Medida Provisória $n^{\circ}$ 934, de $1^{\circ}$ de abril de 2020. Estabelece normas excepcionais sobre o ano letivo da educação básica e do ensino superior decorrentes das medidas para enfrentamento da situação de emergência de saúde pública de que trata a Lei $\mathrm{n}^{\circ}$ 13.979, de 6 de fevereiro de 2020. Diário Oficial da União: 01/04/2020, Edição: 63-A, Seção: 1, Extra, Página: 1, Brasília, DF, 2020.

BRASIL. Decreto Legislativo $\mathrm{N}^{\circ}$ 6, DE 2020. Reconhece, para os fins do art. 65 da Lei Complementar $\mathrm{n}^{\circ}$ 101, de 4 de maio de 2000, a ocorrência do estado de calamidade pública, nos termos da solicitação do Presidente da República encaminhada por meio da Mensagem $n^{\circ}$ 93, de 18 de março de 2020. Diário Oficial da União: DE 20/03/2020, P. 1 - Edição Extra - C, Brasília, DF, 2020.

BRASIL. Ministério da Educação. Portaria nº 343, de 17 de março de 2020. Dispõe sobre a substituição das aulas presenciais por aulas em meios digitais enquanto durar a situação de pandemia do Novo Coronavírus - COVID-19. Diário Oficial da União: 18/03/2020, Edição: 53, Seção: 1, Página: 39, Brasília, DF, 2020.

Instituto Nacional de Estudos e Pesquisas Educacionais Anísio Teixeira. Sinopse Estatística do Questionário Resposta Educacional à Pandemia de Covid-19 no Brasil Educação Básica. Brasília: Inep, 2021. Disponível em: https://download.inep.gov.br/censo_escolar/resultados/2020/apresentacao_pesquisa_covid 19 censo escolar 2020.pdf. Acesso em: 27 set. 2021. 
FREITAS, Luis Carlos de. A reforma empresarial da educação: nova direita, velhas ideias. São Paula: Expressão Popular, 2018.

MOREL, Ana Paula Massadar. Negacionismo da Covid-19 e educação popular em saúde: para além da necropolítica. Revista Trabalho, Educação e Saúde [online]. 202 1, v. 19. Acesso em: 28 set. 202 1, e00315147. Disponível em: https://doi.org/10.1590/1981-7746solo0315. Acesso em: 27/09/2021. DOI: https://doi.org/10.1590/1981-7746-solo0315.

BROWN, Wendy. Nas ruínas do neoliberalismo - a ascensão da política antidemocrática no ocidente. São Paulo: Editora Filosófica Politeia, 2020.

SAVIANI, Dermeval. A crise política e o papel da educação na resistência ao golpe de 2016 no Brasil. In. Krawczyk, N.; Lombardi, J. C. (Orgs.). O golpe de 2016 e a educação no Brasil. Uberlândia: Navegando Publicações, 2018. 